\title{
Practice and Experience of Novel Coronavirus Pneumonia Online Teaching - - Taking Real Estate Project Planning Based on Dingtalk and Rain Class as an Example
}

\author{
Zhongxiu Liu ${ }^{1}$ \\ ${ }^{1}$ School of Civil Engineering and Architecture, Linyi University, Linyi, Shandong 276000, China \\ *Corresponding author. Email: liuzhongxiu@lyu.edu.cn
}

\begin{abstract}
Novel coronavirus pneumonia was attacked in the end of 2019, and online teaching became the norm. Novel coronavirus pneumonia is the key to the development of real estate project. Based on the results of the previous teaching reform, the paper adjusts the time and content of the project according to the characteristics of online teaching, integrates the influence of the new crown pneumonia on the real estate project planning, and optimizes the teaching methods and increases classroom interaction. Online teaching platform selects three kinds of complementary to each other: Dingtalk live broadcast, Rain Class and MOOC. Before, during and after class, the online teaching should be redesigned to increase the interactive links in the classroom, so as to catch the students' attention at all times. The courses assessment adopts Dingtalk online examination and Dingtalk video conference invigilation. Through appropriate red envelope incentive, students' participation and sense of achievement can be improved.
\end{abstract}

Keywords: online teaching, Dingtalk, Rain Class, MOOCS, Real Estate Project Planning

\section{INTRODUCTION}

2019The novel coronavirus pneumonia struck at the end of the year. The Ministry of education put forward the idea of "suspension of classes and non-stop of teaching". Linyi University will promote online teaching orderly in the spring semester of 2020 to ensure the homogeneity and equivalence of online and offline, and minimize the impact of the epidemic on teaching.

"Real estate project planning" was established as a school-level classroom teaching mode reform courses in 2017, and has published two teaching and research papers[1-2] on curriculum reform, straightening out the concept of curriculum construction, optimizing the teaching content, improving the teaching methods and strengthening the process assessment.

\subsection{Curriculum Construction Concept}

After several years of continuous exploration, the curriculum reform has established the concept of curriculum construction based on work process design, project guidance, task driven teaching method, and the combination of theory and practice. Courses theory teaching, practical training practice, courses design and other contents are all around the workflow of real estate project planning. From the acquisition of land use rights, to market research, consumer psychological behavior analysis, market positioning, building planning, pricing strategy, advertising strategy, sales strategy, etc., until the early intervention of property management.

\subsection{Optimization of Teaching Content}

The courses content highlights the key points and optimizes and decomposes the practical training part. Through the collective discussion of the teaching and research section of real estate development and management, college demonstration, industry associations, real estate experts and representatives of school enterprise cooperation enterprises are invited to discuss and revise the syllabus. The key and difficult points of the revised syllabus and teaching content are more prominent. The contents that students can learn through self-study are put into self-study after class. Some cases are released in advance, and questions are tested and answered in class. The training part is divided into classroom training and sand table simulation. Class training students are divided into groups to carry out field research in enterprises and project sites, complete the designated training 
projects, and mobilize students; interest and enthusiasm in learning. Sand table simulates the operation of real estate enterprises. Students play different roles in real estate enterprises and cultivate team spirit, cooperation ability and win-win concept. In the courses design part, a plot is selected to complete the whole process planning of real estate project to help to improve the planning.

\subsection{Diversified Teaching Methods}

Classroom teaching methods are mainly teaching method, discussion method, case analysis method, task teaching method and practical training teaching method. In terms of teaching methods, it emphasizes the central position of students, guides students to explore the answers to questions, forms a good learning atmosphere through group discussion, discussion and learning together, and improves the participation and satisfaction of all students.

\subsection{Diversified Assessment Methods}

"N+1+1" examination mode is implemented in the courses, and the process assessment is strengthened. $\mathrm{N}$ is a variety of process assessment forms, including classroom notes, classroom questioning, discussion, attendance, homework, etc., accounting for $50 \%$ of academic performance; the first "1" is the final examination of the courses, which is generally in the form of open book examination, which allows students to make simple application on the basis of mastering the main knowledge points of the courses, accounting for $30 \%$ of the academic performance; the second "1" is a special combination of specialty and curriculum characteristics Color test, that is, to choose a real estate plot, to group as a unit for the whole planning of real estate projects, and reply comments, accounting for $20 \%$ of the academic results. Pay attention to the evaluation of students; learning process, properly evaluate students; theoretical knowledge and practical operation skills, and the evaluation means and forms are diversified.

\section{ADJUSTMENT OF ONLINE TEACHING}

\subsection{Adjustment of Online Teaching Content}

\subsubsection{Class hour and content adjustment}

The courses have 48 class hours, including 16 theoretical hours and 32 practice hours. Due to the change to online teaching, the sand table simulation courses in practical training can only be conducted after students return to school. Therefore, online teaching is changed to 32 class hours for theory and 16 class hours for practical training. In the training part, students are required to plan four times in groups and watch the teaching video of sand table simulation courses once. In this way, we need to increase the online discussion, case analysis, classroom $\mathrm{Q} \& \mathrm{~A}$, etc. The influence of new epidemic situation on real estate project planning was added into the teaching content.

\subsubsection{Integrating novel coronavirus pneumonia into teaching content}

It can be combined with the innovation of real estate project planning, including concept, product, price, advertising, marketing, property and other aspects, such as the concept of health, health, environmental protection, ecology, green and so on. Through classroom discussion, homework and other forms, let students keep pace with the times and deeply understand and master. In the training work, the real estate research should strengthen personal protection and take the initiative to fight the epidemic; in the marketing activity planning, it is necessary to remind customers to sweep the code, disinfect, wear masks and make an appointment from the perspective of the marketing company; in the theme concept and image planning, the health attributes of products should be emphasized to meet the health and safety needs of customers; the price strategy should be innovated in the price planning, such as anti-epidemic. Additional discount for medical staff, donation reflecting corporate responsibility, food delivery and disinfection, etc.

\subsection{Adjustment of Online Teaching Methods}

Online teaching is realized by building virtual simulation online classroom. The advantage is that as long as there is network, computer or mobile phone, teachers and students can carry out teaching smoothly without space limitation. The disadvantages are also obvious. It is difficult for teachers to master the classroom atmosphere and students; reaction, and students are easily distracted by the lack of teacher atmosphere when facing the screen for a long time. This requires teachers to adjust teaching methods in time, and add interactive teaching such as examination questions, discussion questions, unit tests and even wheat in the classroom, so as to catch students; attention and improve their participation and learning efficiency.

\subsection{Adjustment of Online Teaching Assessment Methods}

In the way of assessment, we should strengthen the usual assessment. The attendance is determined by the 
length of time the students watch the video online. After the live broadcast, the software will automatically generate the background data of the live broadcast, and the students who ask for leave can also learn from me by watching the playback. Due to the reduction of training hours, the proportion of training achievements has also decreased from $20 \%$ to $10 \%$. The unit test part is added, and the unit test accounts for $10 \%$.After this adjustment, the academic performance is $10 \%$ of class notes, $10 \%$ of watching video time, $10 \%$ of individual homework, $10 \%$ of unit test, $10 \%$ of practical training homework and $50 \%$ of open book examination. From a variety of aspects to form the usual results, urge students to complete all kinds of homework on time.

\section{ONLINE TEACHING MODE SELECTION: DINGTALK + RAIN CLASS + MOOC}

Modern information technology has a profound impact on our life and study. Rich network platform, resources and information provide great convenience for teachers and students to teach and acquire knowledge. There are many online teaching platforms, such as Dingtalk, Tencent Classroom, Rain Class, Learning Link, and MOOCS of China University. Each platform has different functions and outstanding advantages. After carefully comparing each teaching platform, combining with the characteristics of the courses, and constantly groping for improvement, the online teaching method of "Dingtalk live [3] + Rain Class + MOOC [4]" is finally selected. Using Dingtalks to establish class group, become online virtual classroom. After experiencing the discomfort of online teaching, teachers and students quickly entered the role.

Through the Dingtalk release preview homework, play ppt courseware for voice live broadcast, set questions in the courseware for classroom interaction, upload courseware and extracurricular reading materials after class, assign correction homework, complete the training task with flipped classroom mode of MAC + screen sharing, etc. Dingtalk live broadcast platform network smooth, timely feedback function is general, and Rain Class has a strong teaching timely feedback function. There are nine chapters in the courses, each of which is tested once every three chapters. Through the Yangtze River Rain Class, the periodical chapter test is not only a test of students; learning effect, but also a test of teaching effect. In addition, during the epidemic period, many online teaching resources were free of charge. In order to make full use of these resources, some videos of MOOC in Chinese universities, real estate foundation - house purchasing dictionary, were selected to play in combination with the courses content. The MOOC video was 3-5 minutes each, mainly in the form of animation, supplemented by cases. It was vivid. The teacher explained in simple terms, and students absorbed and learned more easily.

\section{ONLINE TEACHING PROCESS}

\subsection{Preparation before Class:}

\subsubsection{Electronic textbooks}

Novel coronavirus pneumonia raid, because many students do not have paper textbooks, so they download electronic textbooks and send them to students in advance. Can arrange preview, review, reading materials, thinking and other homework.

\subsubsection{Recommendation of workplace Drama}

Before class, it is recommended that you watch the hit workplace TV series "settling down", starring Sun Li and Luo Jin, so that you can know your career prospects in advance and have a basic understanding of your own occupation, knowledge you may need and problems you may encounter.

\subsubsection{Sign in}

Send a lucky red envelope a few minutes in advance to remind students to sign in for class and prepare for the exam on time.

\subsubsection{Homework}

Use the Dingtalk group to remind students to submit the personal assignment and group training assignment assigned last week in time. Personal homework is uploaded by taking photos of the operation module. The group training assignments are 3 times in total. The whole class is divided into 6 groups, which are submitted in the form of PPT, and the group representatives give explanations online. Half of the students in the class can participate in Lianmai.

\subsection{Live Broadcast of the Courses:}

\subsubsection{Trial broadcast}

Before the formal class audition, let the students deduct the number and other forms to determine the attendance of students, the sound size, whether there are network jams and other phenomena. Lianmai 
audition 15 minutes in advance to the six students who want to speak.

\subsubsection{Dingtalk video live}

Explain the key points, difficulties and Q \& A to improve the quality of classroom learning.

\subsubsection{Increase classroom interaction and bonus.}

According to the characteristics of online teaching, the teaching design is updated. According to the principle of "one sex for one time" issued by the Ministry of education, more than ten interactive links are added to each class, including single choice, multiple-choice questions and thinking questions in the courseware, oral questions from teachers, and answers by students through screen. Ensure that under the condition of distance teaching, students can actively concentrate their attention, actively participate in classroom teaching activities, and improve the teaching effect. In order to better motivate students, the first correct answer to the students for the red envelope award. [5]

\subsubsection{Unit test of Changjiang Rain Class}

There are nine chapters in this courses. Each chapter has a stage test. The test questions are all selfcontained questions, which have been done in the courseware and the Dingtalk live broadcast. After partial modification of the question stem and options, the test is conducted in the Yangtze River Rain Class. The test results are generated by the timely feedback from the Rain Class. The top three good and fast answers will be rewarded with red envelopes.

\subsubsection{Application of MOOC video}

Make full use of network resources, select part of the video of MOOC of China University - "real estate foundation - house purchasing dictionary" to play with the courses content. Or play other contents of the MOOC during recess. It is equivalent to that students' use the time between classes to learn another courses. [6]

\subsubsection{Training of Lianmai + screen sharing}

During the courses of epidemic planning, there is a problem of how to carry out real estate project planning. The teacher arranges the homework through the Dingtalk operation platform, and the students complete the homework in groups of 5-7 people, and selects one representative to give a speech each time.
During the lecture, the teacher applies for Dingtalk the video Lianmai, and the students click on the screen to share, so that other students can see the PPT of the reporting students. After the completion of the report, teachers and students ask questions, group mutual evaluation and other ways to expand and modify. Lianmai has greatly improved the interactivity of the classroom.

\subsection{After Class}

\subsubsection{Announce the viewing time immediately}

After class, immediately release the attendance and video watching time of this class in the nail class group, and urge the students who are not enough in time and ask for leave to watch the video playback

\subsubsection{Send courseware and other materials}

Send the courseware and extracurricular reading materials, and arrange the preview homework before class next week.

\subsubsection{Homework correction}

The assignment module of Dingtalk can set the submission time of homework, and timely supervise the submission of those not submitted on time. Correct the assignments submitted by students on time, give feedback on their assignments, and share excellent assignments so that students can understand the gaps and deficiencies and catch up with them.[7-8]

\subsection{Dingtalk Online Examination System}

The courses increase the strength of process assessment, and improves students; participation and training in the ordinary courses teaching. The final examination is an open book examination, which uploads the examination questions through the Dingtalk platform online, and Dingtalks the video conference for remote invigilation. Students need a computer or mobile phone with a front camera to participate in the Dingtalk video conference and answer questions with another mobile phone. The objective questions will be scored directly according to the uploaded answers, and the subjective questions will be graded by the marking teacher. The system will automatically calculate the total score after all the scoring is completed. 


\section{CONCLUSIONS}

\subsection{Comprehensive Application of Various Online Teaching Platforms}

The combination of Dingtalk, Rain Class and MOOC is complementary to each other. Dingtalk live software is stable and smooth, but cannot timely feedback; Rain Class can be timely feedback to generate support materials for usual performance; MOOC video can be used as a useful supplement to classroom teaching. [9-10]

\subsection{Whole Process Teaching Interaction}

Before, during and after class, the online teaching should be redesigned to increase the interactive links in the classroom, so as to catch the students; attention at all times.

\subsection{Red Envelope Incentive}

Through appropriate red envelope incentive, students; participation and sense of achievement can be improved.

\section{ACKNOWLEDGMENT}

This work was supported by Linyi University 2017 innovation and entrepreneurship education demonstration courses; real estate project planning, and Research project of Linyi University on epidemic prevention and control in 2020: Collaborative development of public health emergency material reserve network in Shandong Province (2020yqsk07)

\section{REFERENCES}

[1] Zhongxiu Liu. Exploration and implementation of case teaching in real estate project planning courses [J]. University education, 2016 (09): 39-40

[2] Zhongxiu Liu. Exploration and practice of classroom teaching mode reform of real estate project planning [J]. Education modernization, 2019, 6 (10): 45-47

[3] Li Ye. Application strategy and evaluation of Dingtalk platform in online English Education [C]. Innovation research on foreign language education and translation development (Volume 9): Sichuan western literature translation research center, 2020:112-114

[4] Deen Lu. Preliminary study on the network live teaching under the mode of "Dingtalk + Rain Class" during the epidemic period -- Taking the teaching of national common language as an example [J]. Classic taste, 2020 (05): 102-103 + 158

[5] Xiaohui Xu. Some ideas on the construction of online open courses -- Taking the courses of real estate market survey and prediction as an example [J]. Economist, 2020 (05): 164

[6] Xuemei Zhang. Preliminary study on the teaching reform of real estate laws and regulations courses based on MOOCS concept [J]. Journal of Chengdu University of traditional Chinese medicine (EDUCATION SCIENCE EDITION), 2019,21 (02): 49-51

[7] Ping Wang, Chang Lin. investigation and practical enlightenment of online teaching in Colleges and universities during epidemic prevention and control period: a case study of Zhejiang University of science and technology [J / OL]. Journal of Zhejiang University of science and Technology (SOCIAL SCIENCE $\quad$ EDITION): 1-9[2020-07-23] http://kns.cnki.net/kcms/detail/33.1338.TS.20200722. 0958.032.html.

[8] Bo Wang, song Yuanming. Teaching reform of materials courses based on online platform [J]. Guangdong chemical engineering, 2020, 47 (14): 201$202+207$

[9] Fang Li. Research on the selection and strategy of effective interactive platform based on Online Teaching [J]. Journal of Anyang Normal University, 2020 (02): 131-133

[10] Yin Gao, Jingyun Zhao, Zhenshen Zhu. Research on online teaching based on multiplatform collaboration $[\mathrm{J}]$. Modern information technology, 2020, 4 (05): 94-96 